\title{
Camille Flammarion (1842-1925): Founder of the Société Astronomique de France
}

\author{
Jacques Pernet \\ (Curator, C. Flammarion Collection at Juvisy Observatory), 5 rue Victor Basch, \\ F-91230 Montgeron, France
}

The long and fertile scientific career of Camille Flammarion, the founder of the Société Astronomique de France, whose centenary we are celebrating in 1987, is marked by an extraordinary variety of projects and research, covering practically all of the astronomical questions and problems that were current in his time. We may cite, as some of the most remarkable: the nine volumes of his Etudes et lectures sur l'astronomie (1867 to 1880); his Catalogue des étoiles doubles et multiples en mouvement relatif certain (1878), summarizing 28000 observations; La planète Mars (2 vols $1892 \& 1909$ ), a priceless documentation of the first martian observations around the beginning of the 20th century; and La planète Vénus, a general discussion of observations (1899).

But to stay within the bounds that we have been set, and which forbid us from expanding our arguments to include an exhaustive study of Flammarion's scientific work, we shall restrict ourselves today to illustrations of his unequalled role in the birth and development of amateur astronomy, first as a fervent amateur himself and then, and primarily, as the enthusiastic innovator, who was the inspiration for innumerable people to take up astronomy as a vocation.

It is a self-evident truth to speak of Flammarion's passion for the observation of the sky. In his Mémoires d'un astronome (1911), he is delighted to recall that, at the earliest age, he was most impressed by two astronomical events, "as rare as they were impressive" as he describes them: two eclipses of the Sun (those of 1847 October 9 and 1851 July 28) that his mother showed him from his birth-place at Montigny-le-Roi (Haute-Marne).

So we shall not be surprised that in 1866, in Paris, when his financial situation was far from being brilliant, he did not hesitate in acquiring a 108-mm refractor, an instrument that was very respectable in size for that time. "Passionately," he says, "I started to observe and draw sunspots, the strange lunar features, the appearance of Jupiter, of Saturn, of Mars, star clusters, and double stars". And he adds a little farther on: "Those who have not tasted the pleasure, the happiness, of astronomical observation, just cannot imagine their utterly fascinating interest."

In 1882, he received, from an admirer of his work, the gift of an enormous property sited at Juvisy-sur-Orge, about twenty kilometres from Paris. His generous donor stated that he could do just as he liked with it, and even sell it again if he so wished. Flammarion did no such thing. Instead, without losing any time, and devoting 
the larger part of his income to it, he started to turn it into a well-equipped scientific establishment. In particular it had an excellent 240-mm equatorial, with which he, and other very talented observers, such as Antoniadi and Quénisset, obtained magnificent results.

It is obvious that Flammarion had the "sacred fire" that inspires selfless investigators. We must, moreover, not forget that from the $1880 \mathrm{~s}$, the popularization of astronomy, and bringing it to be understood and loved by his readers (through such introductory works as le Merveilles célestes 1866, Histoire du ciel 1872, and Les terres du ciel 1877), only ever appeared as the first step. In 1879, in the last pages of his famous Astronomie populaire he wrote: "It is not necessary to possess complicated and expensive instruments in order to begin the practical study of the sky, and we may even note that a large number of discoveries in physical astronomy have been made by ordinary amateurs, using very modest instruments." He then goes on to describe the possibilities for 61-, 75-, 95- and 108-mm refractors, respectively, and for a 100 -mm reflector, adding the names and addresses of manufacturers and the price of each instrument. And he ends: "It will be seen that in our days the practice of the most beautiful of all sciences is accessible to anyone: nowadays we may well say that we have an embarrassing range of choice."

This encouragement towards a more "active" astronomy was re-emphasized in the supplement to Astronomie populaire, les Etoiles et les curiosités du ciel, which appeared the following year. After the first section devoted to the detailed description of each constellation, the second part, entitled "Various documents, instructions, tables and catalogues" essentially describes the sky for each day in the year observations that can be made of the planets, the Moon, and the Sun; observational instruments and the practical study of the sky; a general catalogue of stars; lists of double stars and variable stars - a complete set of practical information that, collected here for beginning observers, gave them a head start.

Once he had begun, and as if to confirm the new direction of his popularization, in 1882 Flammarion started a monthly publication, $L^{\prime}$ Astronomie, the centenary of which we celebrated in 1982. This was a specifically astronomical magazine, and the whole project might seem somewhat premature, but it was an immediate success and the circulation was over 6000 from 1883 onwards. In the notice to his readers that appeared in the first issue, Flammarion was careful to state "Observers of the heavens - who are beginning to become quite numerous - who have made useful observations may publish them here. In each issue a specific section will be reserved for correspondence."

For the first time, amateurs had the means of getting to know one another, and to publish their observations and investigations, however modest or elementary they might be. They were no longer condemned to the relative isolation of small circles of acquaintance in remote provinces: L'Astronomie was distributed even beyond our national boundaries and came to be a link between them.

Another interest for the readers of L'Astronomie was that of being provided, each month, with detailed ephemerides that included, quite apart from details of the visibility of the constellations for that particular month, instructions and advice about the observation of the Sun, the Moon, the planets and all the other astronomical phe- 
nomena that were predicted (eclipses, occultations, etc.). Flammarion thus repeated there what he had been publishing regularly in the Magasin pittoresque since 1865 , and we should note that from 1893 the Annuaire astronomique Flammarion was published as a separate volume. Well presented and at a modest price, this yearbook rendered an invaluable service to several generations of observers before finally disappearing in 1966.

We must also mention the planispheres, the charts and globes of the Moon and of Mars that Flammarion prepared, or had prepared from his instructions by skilled specialists such as Léon Fenet, Paul Fouché, and the selenographer Gaudibert. We may well conclude that amateurs, at the end of the last century, had all the material means at their disposal for undertaking whatever form of research interested them. This was, in large part, thanks to the example and the impetus given by Camille Flammarion.

Until 1887, however, he still lacked one other essential, the scientific background and moral encouragement that would come from a national association, which would establish a lively exchange of views between all French-speaking observers, and would give them that stimulus and pride of contributing to the progress of science.

Flammarion was aware of this. He put forward the idea for the first time in 1879 in L'Astronomie populaire. The success of that publication and the others that we have mentioned prompted him to gather together a group of friends who were interested in astronomy on the 28th January, 1887 , and with them, to found an astronomical society. The prospectus of that first meeting clearly set out the aim of the society: "To study the best method of encouraging a love of astronomy in France, and to foster research by all those who are interested in that science."

Officially founded on 20th June 1887 and given state recognition ten years later, the Société Astronomique de France naturally made its founder the first president, and then its general secretary until his death in 1925. The office in the rue Serpente, in the scientific societies building, was, after 1890 , crowned by a dome (a second was added in 1900), and there was a meridian room, a meeting room and a library. Flammarion had long dreamt of a public observatory, and as soon as it was started it became a breeding-ground for young amateurs such as Baldet, Chrétien, Danjon, Quénisset, Rougier and many more.

But this is yet another story and we have insufficient time to spend on describing a whole century that has been so full of incident. We hope that we have shown that Flammarion's was the driving force in the development of the fashionable interest that eventually became amateur astronomy. An experienced observer, who was familiar with the technical problems and the practical aspects of the discipline, after twenty years of popularizing astronomy with great literary talent and undoubted poetic verve, but purely by means of his books, he had the great merit of not shutting himself in his observatory as if in some ivory tower. He was able to see that among those whom he was educating there were many who were able - and moreover expressed a desire - to play a more active part in the great movement of scientific emancipation that occurred at the end of the 19th century. He was himself an ardent proponent of that movement - did he not have inscribed in letters of gold that 
profession of faith that can still be read today on the front of his observatory at Juvisy: AD VERITATEM PER SCIENTIAM?

Beginning astronomers could never have found a better guide than Camille Flammarion to the discovery of the marvels of the universe, nor a better support than that of the Société astronomique de France in encouraging them to persevere.

[A longer article on this subject has been published as: "The observatory at Juvisy", J.C. Pecker and J. Pernet, L'Astronomie, May 1987, p.331 - Eds.] 